\title{
An overview of complications associated with deferoxamine therapy in thalassemia
}

\author{
Bijan Keikhaei $^{\circledR}$, Neda Farmani-Anooshe, Mohammad Bahadoram ${ }^{\circledR}$, Mohammad-Reza Mahmoudian- \\ Sani, Kosar Alikhani ${ }^{\mathbb{D}}$, Ammar Helalinasab ${ }^{\mathbb{D}}$ \\ Thalassemia and Hemoglobinopathy Research Center, Research Institute of Health, Ahvaz Jundishapur University of Medical Sciences, \\ Ahvaz, Iran
}

\section{A R T I C L E IN F O}

\section{Article Type:}

Mini Review

\section{Article History:}

Received: 7 May 2020

Accepted: 24 June 2020

Published online: 17 July 2020

Keywords:

Deferoxamine

Thalassemia

Chelators

\begin{abstract}
A B S T RAC T
Thalassemic syndromes are the most common genetic diseases in the world that are related to blood transfusion and iron overload in the body. In ß-thalassemia major multiple blood transfusions due to ineffective erythropoiesis lead to iron excess in the body. Iron chelating agent deferoxamine is used to treat chronic iron overload in patients with $\beta$-thalassemia in an attempt to reduce morbidity and mortality related to deposition of excess iron in body tissue. However, a very short half-time, the need of repetitive injections and non-specialized distribution in tissues can lead to side effects, such as ophthalmic and renal complications, neurological, skeletal changes and hearing loss, headaches, and infection too. Patients should be monitored periodically for complications. The risk of toxic effects in doses of more than $50 \mathrm{mg} / \mathrm{kg} / \mathrm{d}$ is higher. Keeping deferoxamine therapeutic index can avoid drug overdose and side effects.
\end{abstract}

\section{Implication for health policy/practice/research/medical education}

Deferoxamine is used to treat chronic iron overload in patients with $\beta$-thalassemia. Short half-time of deferoxamine and the need of repetitive injections can lead to side effects. Patients should be monitored periodically for complications. Keeping deferoxamine therapeutic index can avoid drug overdose and side effects.

Please cite this paper as: Keikhaei B, Farmani-Anooshe N, Bahadoram M, Mahmoudian-Sani MR, Alikhani K, Helalinasab A. An overview of complications associated with deferoxamine therapy in thalassemia. J Nephropharmacol. 2021;10(1):e05. DOI: 10.34172/npj.2021.05.

$\mathrm{B}$ eta-thalassemia major is a homozygous form of $\beta$-thalassemia and is a chronic microcytic anemia caused by a mutation in the beta-globulin gene which leads to a deficit in hemoglobin production, early destruction of red blood cells and frequently blood transfusion and increased iron load consequently in patients. This extra iron causes irreversible damage to the organs' body by causing oxidative stress which can lead to heart failure, liver cirrhosis, endocrine problems such as hypothyroidism, hypogonadism and growth problems, and even neurodegenerative diseases such as Alzheimer's and Parkinson's diseases. Iron chelating drugs are needed to reduce iron load. These drugs are available in injectable and oral forms (1). Deferoxamine is the first drug to be used to treat acute iron poisoning and chronic iron overload in people with chronic blood transfusions. The drug after entering the cell binds with the iron, forms a complex called Ferrioxamine, which is easily disintegrated in the body and excreted in urine and stool $(2,3)$. Deferoxamine has doubled the patient's life expectancy. In chronic iron overload, long-term use of this medication reduces the accumulation of iron in the liver and reduces the risk of hepatic fibrosis (4). One of the positive effects of this drug on the endocrine system is a reduction in insulin resistance. Deferoxamine improves, FBS and HbAlc and also B-cell function (5). The chelators that have been approved for treatment have some specific side effects due to the nontargeted distribution in the body. It should be considered that iron is essential for metabolic activities therefore; the dose of the chelators should be adjusted in the way to balance the risk of iron overload and the chelator's overload. Deferoxamine is an effective treatment for iron 
overload in thalassemia patients with cardiac problems due to its excellent effects on reducing iron overload of the heart and reducing the risk of heart failure. However, a very short half-time, the need of repetitive injections and non-targeted distribution in tissues can lead to damage to the brain, lungs, kidneys, eyes, and can cause problems such as peripheral neuropathy, glandular and growth disorders (6). Therefore, according to the high prevalence of $B$-thalassemia major in Iran and the importance of early detection of therapeutic-related complications, we studied and collected the most important side effects of deferoxamine to suggest a good model for the colleagues in treatment.

A wide spectrum of ophthalmic complications has been counted for deferoxamine. The most important of them are lens opacity (cataracts), optic neuropathy, changes in retinal pigment epithelium (RPE), night blindness, and visual field defects (2). Patients treated with deferoxamine may experience acute or sub-acute disturbances in visual acuity, color vision, and scotoma. Pigmented retinopathy is classically macular or peripheral. However, it may rarely be paramacular, papillomacular, or pre-papillary. Doses higher than $50 \mathrm{mg} / \mathrm{kg} / \mathrm{d}$ increase the risk of systemic toxicity (7). Histological studies showed that deferoxamine can enlarges the RPE cells and stretches microvillus or completely perish them. Although all of the toxicities are not dose-related, high doses of deferoxamine for a long time, along with low levels of ferritin, increase the risk of the toxicity (8). According to a study conducted by Derin et al on ophthalmic complications of deferoxamine, the most common disorder was diffuse atrophy of the RPE layer with pigmented spots in the posterior polar region (macular stippling). One of the suggested mechanisms for ophthalmic toxicity of deferoxamine was the complete discharge iron, copper, and zinc from sensory retinal cells, which are important cofactors for intracellular enzymes and normal cell activity (2). Ocular toxicity may be asymptomatic; therefore, periodic ophthalmic examinations should be considered for all the patients. Monthly ferritin measurement and index therapeutic level (dose in body weight divided by ferritin level) below 0.025 reduces ophthalmic toxicity (7).

One of other counted side effects of deferoxamine is hearing problems. In a study of $1835 ß$-thalassemia major patients treated with deferoxamine, the prevalence of hearing loss was $27.3 \%$, which was in both conductive and sensory-neural patterns. The amount of hearing loss is depended on the genetics and duration of deferoxamine consumption and the route of administration. Patients with more than 10 years of deferoxamine injection experience hearing loss more often. High doses of deferoxamine directly cause neurotoxicity or interfere with trace elements due to the high non-binding level of the drug depletion of trace elements induced by deferoxamine in patients with thalassemia. Like ophthalmic toxicity, doses higher than $50 \mathrm{mg} / \mathrm{kg} / \mathrm{d}$ increase the risk of auditory toxicity (9). However, cases of autotoxicity have been reported even at the doses below $50 \mathrm{mg} / \mathrm{kg} / \mathrm{d}$. A study on 100 injecting-depended thalassemia patients, found that $3 \%$ of patients within the range of index therapy also had hearing loss. Therefore, audiometric evaluation is recommended for patients every six months. Other side effects include tinnitus and deafness, which often are reversible after ceasing deferoxamine $(10,11)$.

Renal complications of deferoxamine in patients with $\beta$-thalassemia major have been investigated in several studies. Patients treated with deferoxamine developed renal tubular and glomerular dysfunction and also decreased filtration rate by increased serum creatinine (12). Other renal complications were seen in $\beta$-thalassemia major include increased $\mathrm{N}$-acetyl-/ $\beta$-glucosaminidase and decreased urinary concentration, as well as increased amino acid and protein excretion. Different mechanisms have been suggested for these side effects, the most likely of which are oxidative effects (13).

Another major side effect of deferoxamine is growth retention and skeletal changes, which are more important in children. Age under three years old and doses above $40 \mathrm{mg} / \mathrm{kg} / \mathrm{d}$ increase the risk of developing this problem. Therefore, it is recommended that doses above $40 \mathrm{mg} / \mathrm{kg} / \mathrm{d}$ not be prescribed until the patient's growth is complete (14).

Transfusion-dependent thalassemia patients experience immune-deficient pathologies, such as phagocytes and lymphocytes impaired functions, due to frequent transfusions and the entry of foreign antigens, as well as the possible absence of spleen. This is one of the factors that predispose these patients to infections, such as sepsis with Yersinia enterocolitica. This infection is common in these patients. A study in Canada on 177 beta-thalassemia major patients over 15 years found that these patients were 5000 times more likely to develop the pathogen $(15,16)$.

Respiratory distress has also been reported rarely in patients treated with high-dose deferoxamine. It should be noted that one of the non-dose-dependent and important side effects of deferoxamine is severe allergy, which occurs as anaphylactic shock and, in weaker states, pain and fever, which can be treated with desensitization in several stages (14).

High dose regimens, or even sometimes in standard regimens have been correlated with neurotoxicity. Several probable mechanisms for neuropathic side effects of deferoxamine have been proposed, such as multiple trace element chelation, metalloenzyme activity inhibition and oxygen based free radical generation $(17,18)$. Monitoring of thalassemia patients presenting with deferoxamine neurotoxicity is difficult. In patients who are asymptomatic or representing slight electrophysiological changes, decreasing the dose with serial monitoring is suggested. In symptomatic cases or cases showing electrophysiological 
deterioration, temporary drug should be discontinued in lower doses with careful re-administration. In addition, deferoxamine treatment has been associated with peripheral neuropathy in thalassemia patients (19). The relevant clinical presentation includes paresthesias, myalgias and muscle weakness, although subclinical involvement detected through neurophysiologic evaluation has been reported (20).

Another important aspect of deferoxamine is contraindications. The contraindications are fungal infections, cataracts, tinnitus, sudden blindness, painful eye movement in upward-looking, severe renal failure, seizure, aluminum intoxication, lactation, and anuria (10). Deferoxamine is the standard treatment for treating patients with iron overload problems, however due to the need for frequent and long-term injections and dosedependent toxic effects, patients should be monitored periodically for these complications. As mentioned, the risk of toxic effects in doses higher than $50 \mathrm{mg} / \mathrm{kg} / \mathrm{d}$ is higher, hence higher doses are not recommended. Regular serum ferritin measurement and maintenance of deferoxamine therapeutic index (0.025) can prevent drug overdose and toxic effects.

\section{Authors' contribution}

All authors passed four criteria for authorship contribution based on recommendations of the International Committee of Medical Journal Editors. BK, MB and NF wrote the main body of the manuscript, MM, KA and $\mathrm{AH}$ significantly participated in the literature review and critically reviewed the manuscript; all the authors approved the final form of the text.

\section{Conflicts of interest}

The authors declare that they have no competing interests.

\section{Ethical considerations}

Ethical issues (including plagiarism, data fabrication, double publication) have been completely observed by the authors.

\section{Funding/Support}

This study was supported by grants from vice chancellor for research affairs, Ahvaz Jundishapur University of Medical Sciences, Ahvaz, Iran.

\section{References}

1. Kang H, Han M, Xue J, Baek Y, Chang J, Hu S, et al. Renal clearable nanochelators for iron overload therapy. Nat Commun. 2019;10:5431. doi: 10.1038/s41467-019-13143-z.

2. Derin S, Erdogan S, Sahan M, Azik MF, Derin H, Topal Y, et al. Olfactory dysfunction in $\beta$ thalassemia major patients treated with iron-chelating agents. Ear Nose Throat J. 2017;96: E8-E12. doi: 10.1177/0145561317096010-1103.

3. Kontoghiorghe CN, Kontoghiorghes GJ. Efficacy and safety of iron-chelation therapy with deferoxamine, deferiprone, and deferasirox for the treatment of iron-loaded patients with non-transfusion-dependent thalassemia syndromes. Drug Des Devel Ther. 2016;10:465-481. doi: 10.2147/ DDDT.S79458.

4. Hider RC, Hoffbrand AV. The role of deferiprone in iron chelation. N Engl J Med. 2018;379:2140-50. doi: 10.1056/ NEJMra1800219.

5. Alnahal AA, Tahan M, Fathy A, Fathy T. Effect of deferoxamine therapy on insulin resistance in end-stage renal disease patients with iron overload. Saudi J Kidney Dis Transpl. 2014;25:808-13. doi: 10.4103/1319-2442.135025.

6. Saliba AN, El Rassi F, Taher AT. Clinical monitoring and management of complications related to chelation therapy in patients with $\beta$-thalassemia. Expert Rev Hematol. 2016;9:151-68. doi: 10.1586/17474086.2016.1126176.

7. Simon S, Athanasiov PA, Jain R, Raymond G, Gilhotra JS. Desferrioxamine-related ocular toxicity: a case report. Indian J Ophthalmol. 2012;60:315-7. doi: 10.4103/03014738.98714.

8. Bui KM, Sadda SR, Salehi-Had H. Pseudovitelliform maculopathy associated with deferoxamine toxicity: multimodal imaging and electrophysiology of a rare entity. Digit J Ophthalmol. 2017;23:11-15. doi: 10.5693/ djo.02.2016.12.001.

9. Badfar G, Mansouri A, Shohani M, Karimi H, Khalighi Z, Rahmati $S$, et al. Hearing loss in Iranian thalassemia major patients treated with deferoxamine: A systematic review and meta-analysis. Caspian J Intern Med. 2017;8:239-49. doi: 10.22088 /cjim.8.4.239.

10. Taher AT, Saliba AN. Iron overload in thalassemia: different organs at different rates. Hematology Am Soc Hematol Educ Program. 2017;2017:265-71. doi: 10.1182/ asheducation-2017.1.265.

11. Tanphaichitr A, Kusuwan T, Limviriyakul S, Atipas S, Pooliam J, Sangpraypan T, et al. Incidence of ototoxicity in pediatric patients with transfusion-dependent thalassemia who are less well-chelated by mono-and combined therapy of iron chelating agents. Hemoglobin. 2014;38:345-50. doi: 10.3109/03630269.2014.940462.

12. Vichinsky E, Torres M, Minniti CP, Barrette S, Habr D, Zhang Y, et al. Efficacy and safety of deferasirox compared with deferoxamine in sickle cell disease: Two-year results including pharmacokinetics and concomitant hydroxyurea. Am J Hematol. 2013;88:1068-73. doi: 10.1002/ajh.23569. Epub 2013 Sep 19.

13. Annayev A, Karakaş Z, Karaman S, Yalçıner A, Yllmaz A, Emre S. Glomerular and tubular functions in children and adults with transfusion-dependent thalassemia. T Turk J Haematol. 2018;35:66-70. doi: 10.4274/tjh.2017.0266.

14. Porter JB. Practical management of iron overload. $\mathrm{Br}$ J Haematol. 2001;115:239-52. doi: 10.1046/j.13652141.2001.03195.x.

15. Al-Kuraishy HM, Al-Gareeb AI. Comparison of deferasirox and deferoxamine effects on iron overload and immunological changes in patients with blood transfusiondependent $\beta$-thalassemia. Asian J Transfus Sci. 2017;11:1317. doi: 10.4103/0973-6247.200768.

16. Lesic B, Foulon J, Carniel E. Comparison of the effects of deferiprone versus deferoxamine on growth and virulence of Yersinia enterocolitica. Antimicrob Agents Chemother. 
2002;46:1741-5. doi: 10.1128/aac.46.6.1741-1745.2002.

17. De Virgiliis S, Congia M, Turco M, Frau F, Dessi C, Argiolu F, et al. Depletion of trace elements and acute ocular toxicity induced by desferrioxamine in patients with thalassaemia. Arch Dis Child. 1988;63:250-5. doi: 10.1136/adc.63.3.250.

18. Klebanoff S, Waltersdorph AM, Michel BR, Rosen H. Oxygen-based free radical generation by ferrous ions and deferoxamine. J Biol Chem. 1989;264:19765-71.
19. Levine JE, Cohen A, MacQueen M, Martin M, Giardina PJ. Sensorimotor neurotoxicity associated with highdose deferoxamine treatment. J Pediatr Hematol Oncol. 1997;19:139-41. doi: 10.1097/00043426-199703000-00008.

20. Economou M, Zafeiriou DI, Kontopoulos E, Gompakis $\mathrm{N}$, Koussi A, Perifanis V, et al. Neurophysiologic and intellectual evaluation of beta-thalassemia patients. Brain Dev. 2006;28:14-8. doi: 10.1016/j.braindev.2005.03.006.

Copyright $\odot 2021$ The Author(s); Published by Published by Society of Diabetic Nephropathy Prevention. This is an open-access article distributed under the terms of the Creative Commons Attribution License (http://creativecommons.org/licenses/by/4.0), which permits unrestricted use, distribution, and reproduction in any medium, provided the original work is properly cited. 